This document is the accepted manuscript version of the following article:

Rowthu, S., Saeidi, F., Wasmer, K., Hoffmann, P., \& Kuebler, J. (2018). Flexural strength evaluations and fractography analyses of slip cast mesoporous submicron alumina. Ceramics Internationa1, 44(5), 5193-5201. https://doi.org/10.1016/j.ceramint.2017.12.125

This manuscript version is made available under the CC-BY-NC-ND 4.0

license http://creativecommons.org/licenses/by-nc-nd/4.0/

\title{
Flexural Strength Evaluations and Fractography Analyses of Slip Cast Mesoporous Submicron Alumina
}

Sriharitha Rowthu ${ }^{1, *}$, Fatemeh Saeidi ${ }^{1}$, Kilian Wasmer ${ }^{1}$, Patrik Hoffmann ${ }^{1}$, Jakob Kuebler ${ }^{2}$

${ }^{1}$ Laboratory for Advanced Materials Processing, Empa, Swiss Federal Laboratories for Materials Science and Technology, Feuerwerkerstrasse 39, CH-3602 Thun, Switzerland

${ }^{2}$ Laboratory for High Performance Ceramics, Empa, Swiss Federal Laboratories for Materials Science and Technology, Ueberlandstrasse 129, CH-8600 Duebendorf, Switzerland

*Corresponding author: haritha.iitm@gmail.com; sriharitha.rowthu@psi.ch

\begin{abstract}
Mesoporous submicron $\alpha-\mathrm{Al}_{2} \mathrm{O}_{3}$ green compacts were fabricated using slip casting of ultrafine alumina powders. The pre-sintered samples were sintered in air atmosphere at $1300{ }^{\circ} \mathrm{C}, 1350{ }^{\circ} \mathrm{C}$, $1400{ }^{\circ} \mathrm{C}$, and $1500{ }^{\circ} \mathrm{C}$ to obtain a variety of grain morphologies namely submicron equiaxed and micro rod structures. The resulting grain diameters lie between $\sim 270 \mathrm{~nm}$ and $\sim 1590 \mathrm{~nm}$ and total porosity fraction between $0.05 \%$ and $13 \%$. The room temperature flexural strength $(\sigma)$ evaluations and fractography analyses of sintered alumina samples were performed. It was observed that the total porosity fraction dictates the flexural strength as compared to grain diameter. Further, it was found that the flexural strength exhibited a decreasing trend for an increase in the total porosity fraction, and proved to be a better effective parameter than open porosity fraction. The fractography analyses suggest that samples sintered at $1300{ }^{\circ} \mathrm{C}$ and 1350 ${ }^{\circ} \mathrm{C}$ predominantly underwent intergranular fracture, while those sintered at $1400{ }^{\circ} \mathrm{C}$ and $1500{ }^{\circ} \mathrm{C}$ underwent a mixture of intergranular and transgranular fracture.
\end{abstract}

Keywords: Flexural strength; Mesoporous alumina; Submicron; Transgranular fracture; Intergranular fracture; Slip casting

\section{Introduction}

Alumina $\left(\mathrm{Al}_{2} \mathrm{O}_{3}\right)$ is one of the most widely used and a well-studied advanced ceramic. The high temperature and high chemical stability of $\mathrm{Al}_{2} \mathrm{O}_{3}$ as well as its strength retention at elevated temperatures makes it an interesting material for many applications [1,2]. Porous ceramics offer high surface area to volume ratio and are potentially interesting as catalyst carriers or filters for

*Currently at Laboratory for Nuclear Materials (LNM), Paul Scherrer Institute (PSI), CH-5232, Villigen, Switzerland. Email Id: sriharitha.rowthu@psi.ch 
molten metals and provide high temperature insulation [1-3]. Further, porous alumina ceramics, when infiltrated with a second phase material such as glass [4],[5], are often used in dental prosthesis applications.

Flexural strength $(\sigma)$ data of alumina materials are widely available, and depend on the pore fraction [1], grain morphology [1],[6], purity, crystallographic orientation [7] and fabrication techniques [8],[9],[10],[11],[12],[13]. Many research efforts were put forth to evaluate flexural strength of equiaxed fully dense $\alpha-\mathrm{Al}_{2} \mathrm{O}_{3}$ samples for varying grain sizes between $1 \mu \mathrm{m}$ and 250 $\mu \mathrm{m}$ [6],[8]. A variety of fabrication routes such as hot pressing [8],[10],[11], hot isostatic pressing [11], cold pressing followed by sintering [9] and slip casting followed by sintering [12],[14],[15] were employed in those studies. Limited literature is available on the flexural strength of non-equiaxed fully dense $\alpha-\mathrm{Al}_{2} \mathrm{O}_{3}$ samples [9]. Although, it has been well established that flexural strength increases with a decrease in the grain size [8],[9],[10],[11], very limited literature is available on the flexural strength of fine grained fully dense $\alpha-\mathrm{Al}_{2} \mathrm{O}_{3}$ samples [16].

Moreover, the flexural strength data of microcrystalline, microporous (pore sizes $>50 \mathrm{~nm}$ ) $\alpha-\mathrm{Al}_{2} \mathrm{O}_{3}$ samples were reported by few researchers [1],[4],[14],[15] and quantitative relations [17-20],[21] have been developed to predict strength as a function of total porosity fraction. In addition, some works were carried out on highly porous fine grained (500 nm [1] and $700 \mathrm{~nm}$ [14]) $\mathrm{Al}_{2} \mathrm{O}_{3}$ foams constituting $90 \%$ to $94 \%$ total porosity fraction [1]. These studies indicate that a decrease in the pore size results in an increased flexural strength. However, there is no literature available on the effect of mesoporous (pore sizes between $2 \mathrm{~nm}$ and $50 \mathrm{~nm}$ ) network on the flexural strength of $\alpha-\mathrm{Al}_{2} \mathrm{O}_{3}$ samples. Therefore, the focus of the current study is to evaluate the flexural strength of submicron alumina samples in conjunction with mesoporous structure and perform fractography analyses.

Slip casting is often used and a cost effective technique to obtain bulk porous ceramics as well as surface hierarchical micro and nano scale porosities [22],[23]. This technique can be combined with replication techniques to obtain surface, micro/nano features such as hierarchical porosities, pillars, tear cavities, which can find applications in the field of tribology and wetting [22-24]. Alumina samples synthesized by slip casting were utilized for the fabrication of ceramic crowns 
[25]. In this study, we employed such a widely-used slip casting technique and a sintering process to fabricate mesoporous submicron $\alpha-\mathrm{Al}_{2} \mathrm{O}_{3}$ samples.

\section{Experimental Details}

\subsection{Slip Casting and Sintering}

Ultrafine $\alpha-\mathrm{Al}_{2} \mathrm{O}_{3}$ powders (BMA 15, $99.9 \%$ purity) were commercially obtained from Baikowski, France and were used to synthesize mesoporous alumina samples. The as-received $\alpha-\mathrm{Al}_{2} \mathrm{O}_{3}$ powders from the supplier were agglomerated as can be seen in Figure 1a, and have agglomerate diameters between $10 \mu \mathrm{m}$ and $100 \mu \mathrm{m}$. A zoom in of an agglomerate in Figure 1a reveals the presence of ultrafine grains. Alumina slurry of 25 vol. \% solid fraction was prepared and ultrasonicated with a probe to measure particle size distributions of the de-agglomerated $\alpha-\mathrm{Al}_{2} \mathrm{O}_{3}$ powders using a CPS disc centrifuge, CPS Instruments, Europe, The Netherlands. The de-agglomerated particles (grains in this study), have a median particle diameter, $\mathrm{d}_{v 50}$, between $130 \mathrm{~nm}$ and $150 \mathrm{~nm}\left(\mathrm{~d}_{\mathrm{v} 50}\right.$ means $50 \mathrm{vol} . \%$ of particles have diameters $\left.\leq 150 \mathrm{~nm}\right)$. The particles have a narrow particle size distribution, and majority of the grain diameters lay between $90 \mathrm{~nm}$ and $220 \mathrm{~nm}$ as published earlier [22].

As-received $\alpha-\mathrm{Al}_{2} \mathrm{O}_{3}$ agglomerated powders were employed to prepare 25 vol. $\%$ solid fraction containing alumina suspensions, followed by extensive de-agglomeration using an ultrasonic probe, low energy milling with $1 \mathrm{~mm}$ diameter alumina beads. 1-Octanol, from Sigma-Aldrich, Switzerland was utilized as a surfactant to help easy degassing of the alumina slurry. A polyacrylic acid 65 wt. \% solution (PAA, MW = 2000) obtained from Sigma-Aldrich, Switzerland served as a dispersant in the alumina slurry preparation. The schematic presentation of the slip casting process is presented in Figure $1 \mathrm{~b}$. The dispersed alumina slurry was poured into impermeable Elastosil Polydimethylsiloxane (PDMS) molds to obtain cuboidal samples, upon completion of the drying. The completely de-agglomerated $\alpha-\mathrm{Al}_{2} \mathrm{O}_{3}$ suspension was dried at $90 \%$ relative humidity (RH) for $24 \mathrm{~h}$ and then at $45 \% \mathrm{RH}$ for the next $24 \mathrm{~h}$, which finally resulted in mesoporous $\alpha-\mathrm{Al}_{2} \mathrm{O}_{3}$ green compacts. Complete details of slip casting procedure are described elsewhere $[22,23]$.

The $\alpha-\mathrm{Al}_{2} \mathrm{O}_{3}$ green compacts were then pre-sintered in air at $600{ }^{\circ} \mathrm{C}$ at a heating rate of $1 \mathrm{~K} \mathrm{~min}^{-1}$ with a $1 \mathrm{~h}$ isothermal stage at $600{ }^{\circ} \mathrm{C}$ to remove the PAA dispersant and Octanol surfactant. The pre-sintered samples were subsequently sintered in air at temperatures of $1300 \pm 10{ }^{\circ} \mathrm{C}, 1350 \pm 5$ 
${ }^{\circ} \mathrm{C}, 1400 \pm 5{ }^{\circ} \mathrm{C}$, and $1500 \pm 5{ }^{\circ} \mathrm{C}$ in a tubular furnace at $10 \mathrm{~K} \mathrm{~min}^{-1}$ heating rate, followed by a $1 \mathrm{~h}$ isothermal stage at the highest temperature to achieve relative densities between $87 \%$ and 99.5 $\%$. Alumina green compacts with dimensions of $56 \times 9 \times 7 \mathrm{~mm}^{3}$ finally shrank to approx. $50 \times 8 \times 6$ $\mathrm{mm}^{3}$, post sintering. The apparent total density and open porosity of at least 10 samples from each of the sintering batches were estimated using Archimedes principle with water as the suspending and impregnating liquid medium at $23 \pm 2{ }^{\circ} \mathrm{C}$ and $35 \pm 10 \% \mathrm{RH}$. Water impregnates into open porous network and the dry weight, wet weight and immersed weights of the sample are measured. Mathematically, the open porosity fraction and the relative density values are estimated using Equations (1) and (2), respectively [26]. The reader may also refer to supporting information for the derivations of the Equations (1) and (2). The total porosity and closed porosity fractions are eventually estimated using the open porosity fraction and relative density values. Similarly, the apparent density of pre-sintered samples was measured using isopropanol as the suspending liquid medium.

$$
\begin{gathered}
\text { Open porosity }(O P, \text { in } \%)=\frac{\text { wet weight }- \text { dry weight }}{\text { wet weight }- \text { immersed weight }} \times 100 \\
\text { Relative density }(\%)=\frac{d r y \text { weight } \times \text { liquid density }}{(\text { wet weight }- \text { immersed weight }) \times \text { full solid density }} \times 100
\end{gathered}
$$

\subsection{Microstructural Characterizations}

Alumina samples were characterized with a Hitachi S4800 high resolution scanning electron microscope (HRSEM) in secondary electron (SE) mode with $1.5-5 \mathrm{keV}$ and $10 \mu \mathrm{A}$ to obtain the grain and pore morphology at all the processing stages and also to carry out fractography analyses. The pore size distributions of cylindrical shaped ( $3 \mathrm{~g}$ weight) porous alumina samples were determined using a Hg intrusion porosimeter (Pascal 440, Germany).

\subsection{4-Point Bending Experiments and Sample Preparation}

The 4-point bending technique is well-established to evaluate the flexural strength of ceramics, [27] and therefore was chosen in the current study. The flexural strength values of $>50$ alumina samples, at least 10 samples from each of the sintering temperatures $\left(1300^{\circ} \mathrm{C}, 1350{ }^{\circ} \mathrm{C}, 1400{ }^{\circ} \mathrm{C}\right.$ and $1500^{\circ} \mathrm{C}$ ), were measured with 4-point bending setup as shown in Figure 1c. It was extremely 
tedious and time consuming to carry out grinding experiments, thereby Weibull distribution could not be performed. The sample preparation was in accordance with the ASTM C1161-13 standard [27], wherein all the sides of sintered samples were ground with diamond wheels in parallel to the length direction. Subsequently, all the edges of the samples were chamfered to $0.12 \pm 0.03 \mathrm{~mm}$ length at $45 \pm 5^{\circ}$. Eventually, the recommended dimensions as per the ASTM C1161-13 standard [27] were achieved i.e. minimum length of $45 \mathrm{~mm}$ and up to $50 \mathrm{~mm}$, width (w) of $4 \pm 0.13 \mathrm{~mm}$ and thickness (t) of $3 \pm 0.13 \mathrm{~mm}$. The samples were subsequently ultrasonicated in ethanol for 30 mins to remove any loosely adhered particles as a result of grinding process and eventually dried in oven at $150{ }^{\circ} \mathrm{C}$ for $5 \mathrm{~h}$. The flatness measurements were performed on each side of all the samples using a white light AltiProbe Optic ${ }^{\circledR}$ profilometer and are less than $15 \mu \mathrm{m}$ across $\sim 50 \mathrm{~mm}$ length of the samples as recommended by ASTM C1161-13 standard [27]. The arithmetic mean roughness $\left(R_{a}\right)$ values of sintered samples were also measured with the same profilometer according to the standard DIN EN ISO 4287, ASME B46.1. A total of 9 measurements from 3 samples representing each of the sintering temperatures were performed. The measured $\mathrm{R}_{\mathrm{a}}$ values are $0.32 \pm 0.07 \mu \mathrm{m}, 0.22 \pm 0.05 \mu \mathrm{m}, 0.34 \pm 0.18 \mu \mathrm{m}$ and $0.23 \pm 0.05 \mu \mathrm{m}$ for $1350{ }^{\circ} \mathrm{C}, 1400{ }^{\circ} \mathrm{C}, 1450{ }^{\circ} \mathrm{C}$ and $1500{ }^{\circ} \mathrm{C}$ sintered samples respectively. The four-point bending tests were carried out using $40 / 20 \mathrm{~mm}$ load geometry at room temperature $\left(23 \pm 2{ }^{\circ} \mathrm{C}\right)$ and $60 \%$ $\mathrm{RH}$, with a cross-head displacement speed of $0.5 \mathrm{~mm} / \mathrm{min}$ on a universal testing machine: Zwick Z005, Germany. An increasing normal load is applied in a typical 4-point bending experiment, until the sample fractures. The average time till the fracture was $\sim 10 \mathrm{~s}$. Load versus time data is recorded and the highest load at which the sample fractures is used to calculate the flexural strength of alumina samples. 

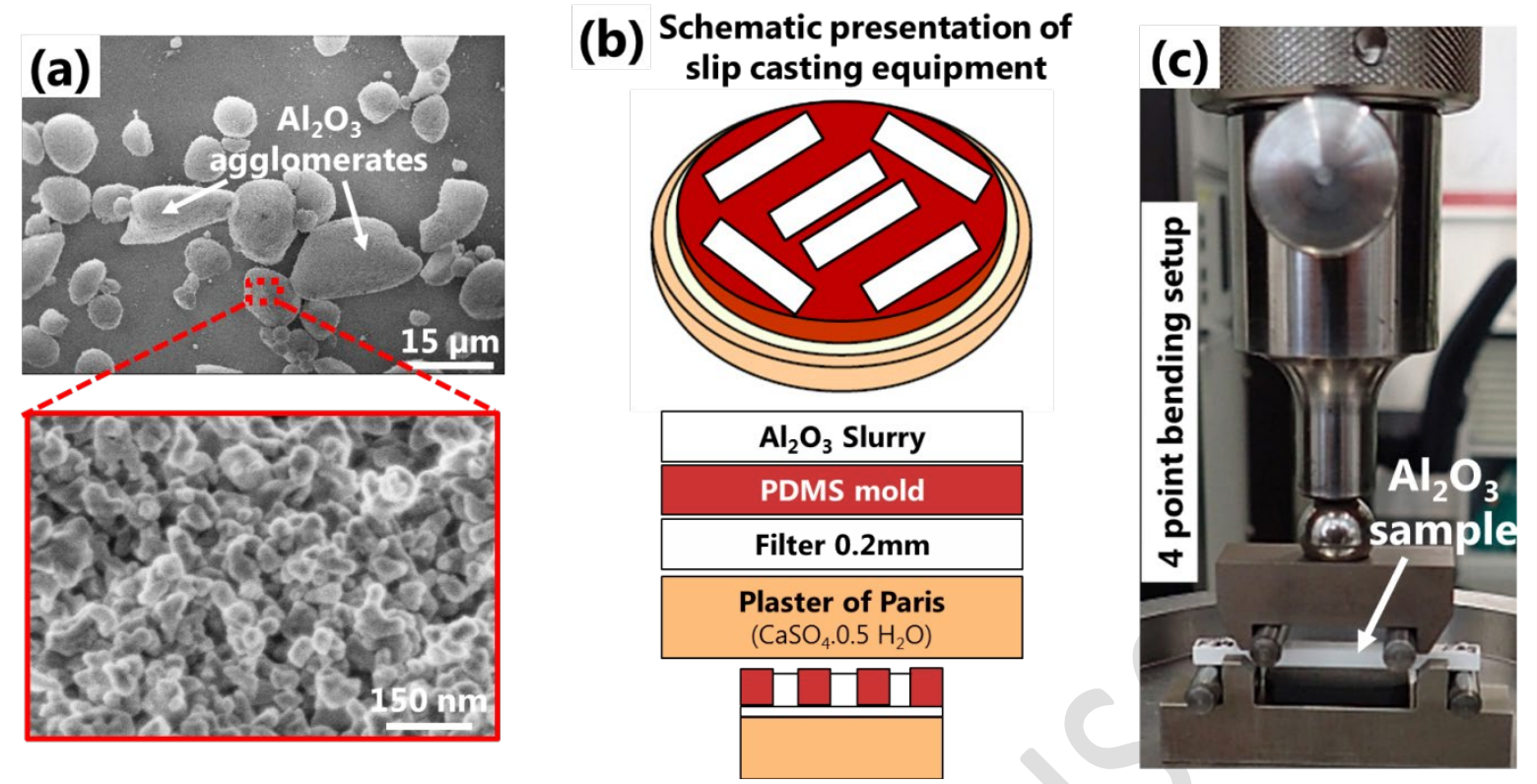

Figure 1. (a) Low and high magnification SEM images of as-received $\alpha-\mathrm{Al}_{2} \mathrm{O}_{3}$ powders from the supplier showing several agglomerates, which contain ultrafine grains, (b) schematic presentation of slip casting equipment, and (c) a picture of the 4-point bending experimental setup.

\section{Results and Discussion}

It is known that the porosity fraction [17-20], the average pore size [14] and distributions [1], the grain morphology [8],[9],[10], the sample fabrication procedure [11], and the sample surface finish prior to bending experiments $[5,9,27,28]$ are the critical influencing factors in determining the flexural strength of brittle ceramics. In this study, the sample fabrication procedure and the sample surface finish were kept constant. The total porosity fraction, pore sizes and grain morphology are the main varied parameters. In this section, the microstructural characteristics, the flexural strength data and the fractography analyses of alumina samples will be presented as function of sintering temperatures, porosity fraction and grain morphology. Further, the evaluated flexural strength will be compared with collected literature data.

\subsection{Microstructural Characterizations}

A representative SEM image of mesoporous $\alpha-\mathrm{Al}_{2} \mathrm{O}_{3}$ pre-sintered samples is shown in Figure $2 \mathrm{a}$. They possess ultrafine equiaxed grains and have $\sim 60 \%$ relative density. The pre-sintered compacts have also the same grain size distribution as that of de-agglomerated powders, i.e. possessing a narrow size distribution and average grain diameter of $150 \pm 25 \mathrm{~nm}$. 
They were subsequently sintered to obtain samples with varying pore fraction and grain morphology. The sintering temperatures $\left(T_{\text {sint }}\right)$ were $1300{ }^{\circ} \mathrm{C}, 1350{ }^{\circ} \mathrm{C}, 1400{ }^{\circ} \mathrm{C}$, and $1500{ }^{\circ} \mathrm{C}$, which correspond to $\sim 0.68 T_{\mathrm{m}}, \sim 0.7 T_{\mathrm{m}}, \sim 0.72 T_{\mathrm{m}}$, and $\sim 0.76 T_{\mathrm{m}}$ respectively, where $T_{\mathrm{m}}$ is melting point of $\alpha-\mathrm{Al}_{2} \mathrm{O}_{3}$ and equal to $2050{ }^{\circ} \mathrm{C}$. The average relative density (\%) values of the sintered alumina samples are presented as a function of sintering temperature in Figure 3a. It can be observed that the density increased from $93 \pm 2.6 \%$ to $97 \pm 2 \%$ with an increase in sintering temperature from $1300{ }^{\circ} \mathrm{C}$ to $1400{ }^{\circ} \mathrm{C}$.

Although the standard deviation in average density values is only $2.6 \%$ for samples sintered at $1300{ }^{\circ} \mathrm{C}$, the absolute values range between $87 \%$ and $96 \%$ (not shown). Similarly, for those sintered at $1350{ }^{\circ} \mathrm{C}$ and $1400{ }^{\circ} \mathrm{C}$, the relative density values lie between $90 \%$ and $97.5 \%$; and $94.5 \%$ and $99.5 \%$, respectively. Full densification could be attained at just $1400{ }^{\circ} \mathrm{C}\left(0.72 \mathrm{~T}_{\mathrm{m}}\right)$, smaller than that of microcrystalline $\mathrm{Al}_{2} \mathrm{O}_{3}$ powders [11], due to the large surface energy of ultrafine alumina particles available during sintering and a high initial green compact density ( $\sim 60 \%$ ) prior to sintering processes in our study, as compared to that of loose $\mathrm{Al}_{2} \mathrm{O}_{3}$ powders in literature [11]. This is because the green compact densities in the pressureless slip casting process are a resultant of fabrication process parameters such as slurry viscosity, solid weight content in the slurry, and initial grain sizes of the powders, their grain size distributions and the extent of slurry dispersion.[29-32] Eventually, higher sintered densities can be attained with higher green compact densities for same sintering temperatures as also reported for $\alpha-\mathrm{Al}_{2} \mathrm{O}_{3} \quad[29,30,32]$. Alternatively, lower sintering temperatures are sufficient for highly compact green bodies to achieve full densification as compared to that of low density green bodies or loose powders which is also valid for $\alpha-\mathrm{Al}_{2} \mathrm{O}_{3}[29,30,32]$. For the samples sintered at a higher temperature of $1500{ }^{\circ} \mathrm{C}$, the attained average relative density values are $97.97 \pm 0.86 \%$, suggesting not much increase in the relative density values as compared to that of $1400{ }^{\circ} \mathrm{C}$ sintered samples (Figure 3a).

The representative 2D SEM cross-sectional images of sintered samples at each sintering temperature are presented in Figure 2(b-e). Evidently from this figure, for samples sintered at $\leq$ $1400{ }^{\circ} \mathrm{C}$, the grains are equiaxed and sub-micron, while those sintered at $1500{ }^{\circ} \mathrm{C}$ constitute rod shaped micron-scale grains due to anisotropic grain growth. The grain morphology of samples sintered at $1450{ }^{\circ} \mathrm{C}$ and $1475{ }^{\circ} \mathrm{C}$ were also investigated resulting in rod shaped grains (not shown 
here), suggesting an anisotropic grain growth for sintering temperatures of $>1400{ }^{\circ} \mathrm{C}$. The grain sizes for equiaxed grains are taken as the maximum feret diameter while for anisotropic grains, an equivalent grain size is considered. The equivalent grain size is defined as an equivalent $2 \mathrm{D}$ grain diameter of a circular grain having the same cross-sectional area as that of an irregularly shaped (elongated, in this study) grain obtained from 2D SEM images. The equivalent 2D average grain diameters averaged over at least 300 grains for each sintering temperature are plotted in Figure 3b.

By sintering at $1300{ }^{\circ} \mathrm{C}$, both the grain growth and the bulk densification occurred. The estimated average grain diameter in these samples is $300 \pm 70 \mathrm{~nm}$, and exhibited an increase as compared to that of pre-sintered samples $(150 \pm 25 \mathrm{~nm})$. Also, the grain size distribution has become slightly wider, as evident from the increased coefficient of variance (mean/standard deviation) from 0.083 (pre-sintered) to $0.23\left(1300^{\circ} \mathrm{C}\right.$ sintered batch). For samples sintered at $1350{ }^{\circ} \mathrm{C}$ and $1400{ }^{\circ} \mathrm{C}$, the estimated average grain sizes are $507 \pm 153 \mathrm{~nm}$ and $850 \pm 245 \mathrm{~nm}$ respectively, which indicates a further grain growth. The grain size distributions in both these sintering batches have become wider as compared to $1300{ }^{\circ} \mathrm{C}$ sintered batch. Further, the equivalent grain diameter in samples sintered at $1500{ }^{\circ} \mathrm{C}$ is $1587 \pm 863 \mathrm{~nm}$ revealing micro-crystallinity. The aspect ratio of majority of these rods is $\sim 5$. These rods have a broad size distribution as evident from Figure $2 \mathrm{e}$ and an associated big standard deviation from average grain sizes (Figure 3b). Similar to our observations, anisotropic grain coarsening in micron-grained ( $2 \mu \mathrm{m}$ to $4 \mu \mathrm{m}$ grain diameter) $\alpha-\mathrm{Al}_{2} \mathrm{O}_{3}$ samples was observed [9] at slightly higher sintering temperatures of $\geq 1550{ }^{\circ} \mathrm{C}$. A large scatter in the density values and grain sizes are a result of unavoidable process parameters such as different powder lots, powder handling and the slip casting process itself. 

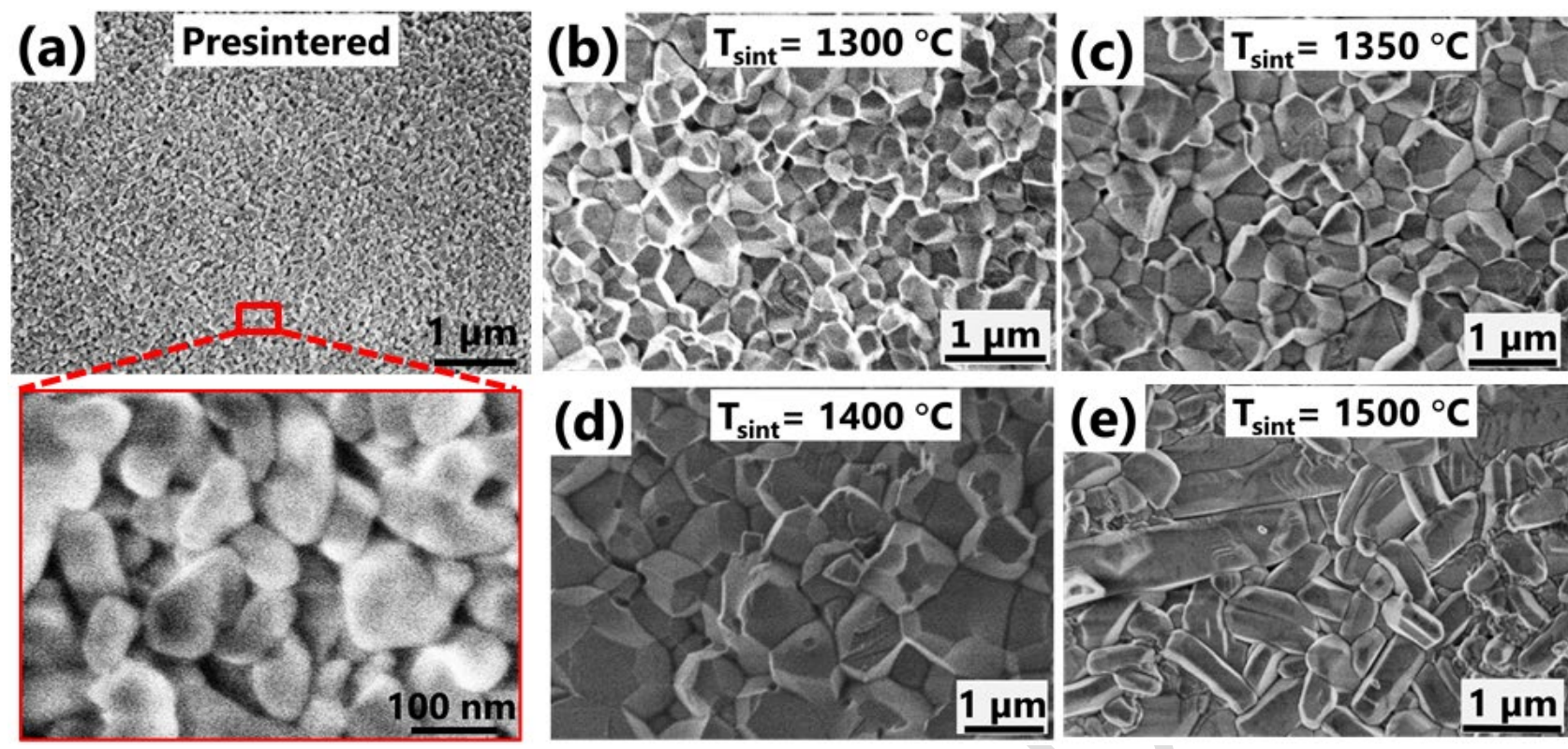

Figure 2. Representative grain morphology of $\mathrm{Al}_{2} \mathrm{O}_{3}$ samples (a) prior to sintering i.e. pre-sintered sample and after sintering at (b) $1300{ }^{\circ} \mathrm{C}$, (c) $1350{ }^{\circ} \mathrm{C}$, (d) $1400{ }^{\circ} \mathrm{C}$, and (e) $1500{ }^{\circ} \mathrm{C}$ respectively.

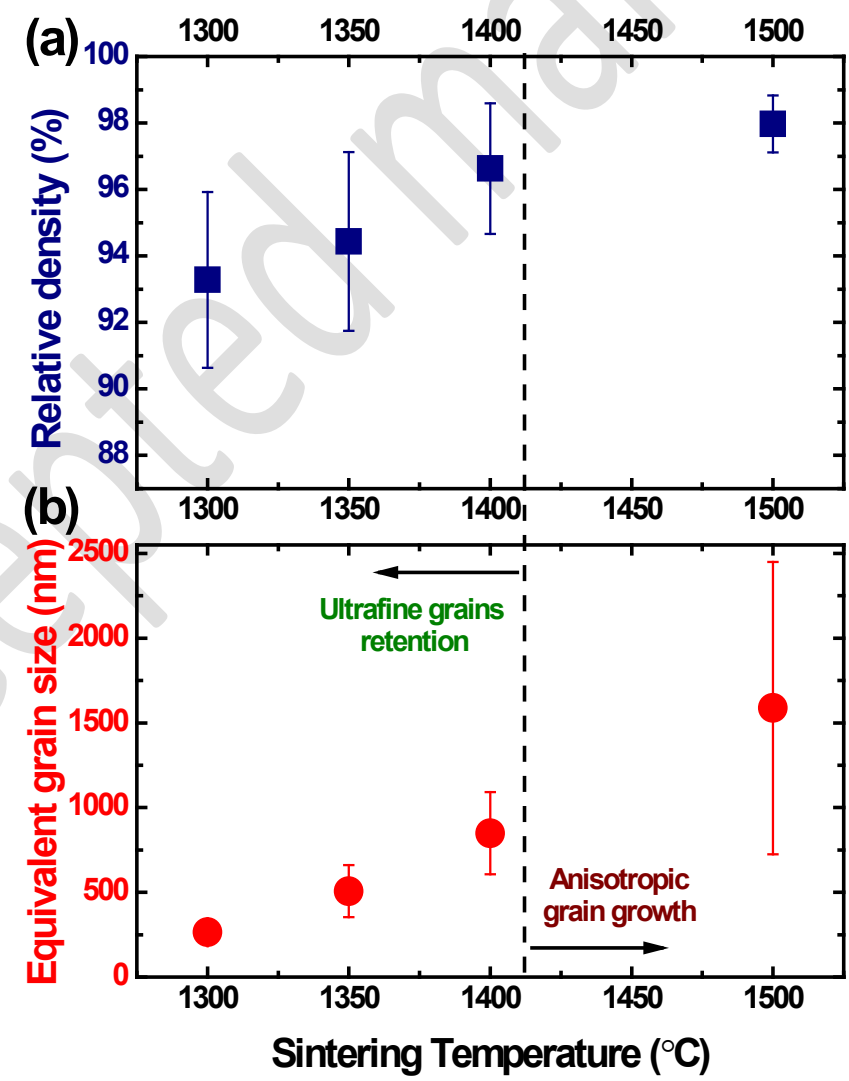

Figure 3. (a) Average relative density values, and (b) equivalent grain sizes of sintered $\alpha-\mathrm{Al}_{2} \mathrm{O}_{3}$ samples plotted as a function of sintering temperature $\left({ }^{\circ} \mathrm{C}\right)$. The samples sintered at $\leq 1400{ }^{\circ} \mathrm{C}$, constitute equiaxed submicron grains while, those sintered at $1500{ }^{\circ} \mathrm{C}$ constitute anisotropic micron-scale grains. 
In addition to the grain morphology, the porosity fraction, the average pore size and the distributions of pores are essential to be determined. Rice R. W. et al., [17-20] suggested that an increase in the total porosity fraction leads to an exponential decrease in the flexural strength of brittle ceramics, while Ryshkewitch, E. [21] proposed open porosity fraction instead of total porosity. Consequently, the open and closed porosity fraction of sintered alumina samples are plotted as a function of sintering temperature in Figure 4a in logarithm 10 scale. This explains why the standard deviations are not symmetrical to the average values. The amount of open and closed porosity in $1300{ }^{\circ} \mathrm{C}$ sintered batch are similar. While in $1350{ }^{\circ} \mathrm{C}, 1400{ }^{\circ} \mathrm{C}$ and $1500{ }^{\circ} \mathrm{C}$ sintered batches, the closed porosity fraction is the major fraction. As expected, the open porosity fraction majorly decreased with an increase in the sintering temperature. For instance, the open porosity in $1300{ }^{\circ} \mathrm{C}$ sintered samples is $3.2 \pm 3.6$ and decreases to $0.11 \pm 0.29$ at $1500{ }^{\circ} \mathrm{C}$. The standard deviations of the porosity values in Figure 4 are a result of measurements from 10 different samples, fabricated using different lots of powder, different sintering batches at different times of the year. As a result, the absolute value of the error is larger than the absolute value of the average porosity fraction value. Already for samples sintered at $1350{ }^{\circ} \mathrm{C}$, the amount of open porosity fraction is as small as $0.04 \pm 0.05 \%$ and therefore, the pore size distribution data could be obtained only for $1300{ }^{\circ} \mathrm{C}$ sintered samples. $\mathrm{Hg}$ intrusion porosimeter measurements were carried out on at least 3 samples and average data is presented in Figure $4 \mathrm{~b}$. The estimated average pore diameters are $18.1 \pm 5.5 \mathrm{~nm}$, assuming cylindrical pores and employing Washburn's equation [22]. The pore size distribution is narrow and reveals the presence of mesoporosity (diameters between $2 \mathrm{~nm}$ to $50 \mathrm{~nm}$ ) in these samples. 

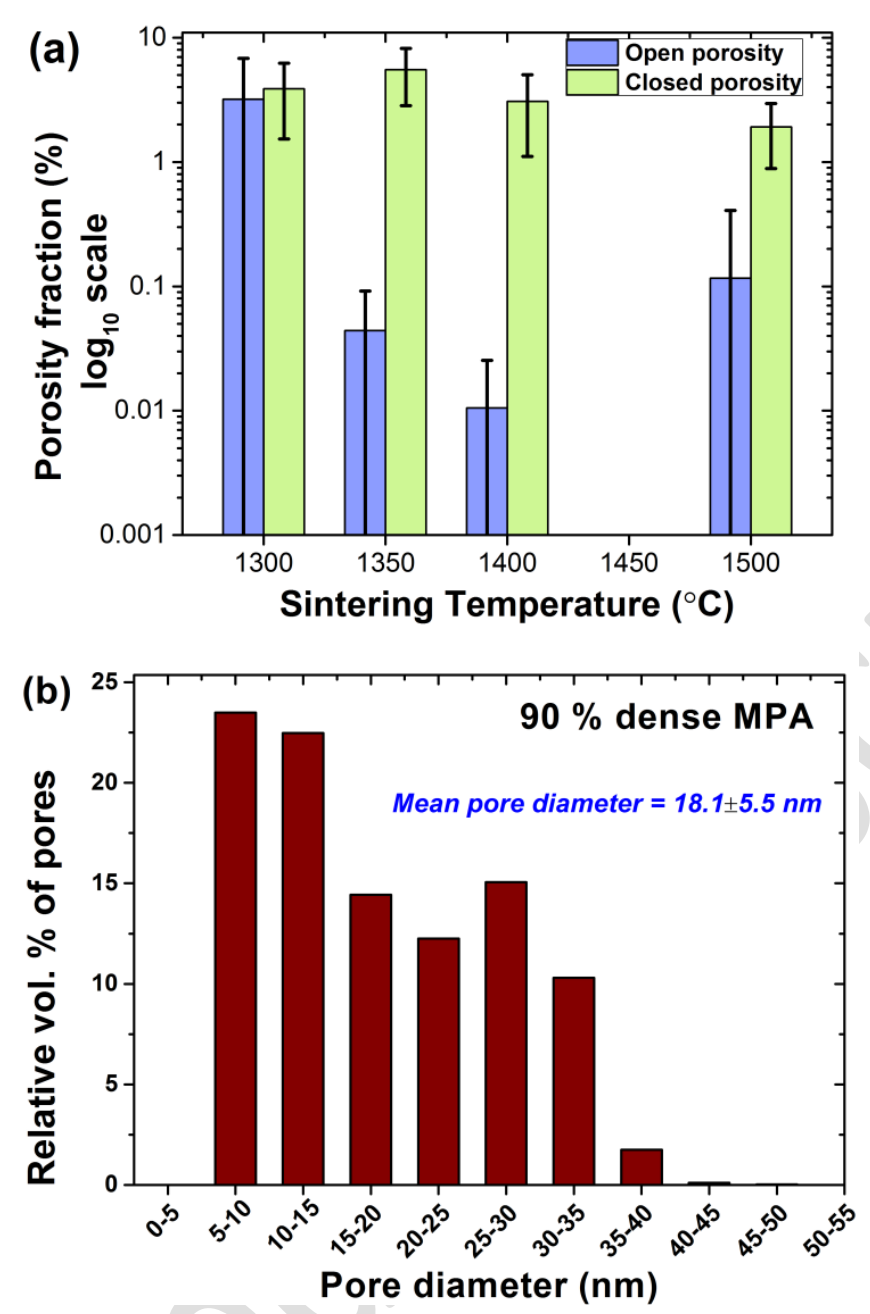

Figure 4. (a) The average values of the open porosity fraction and closed porosity fraction as a function of sintering temperature in the $\log _{10}$ scale are presented. Note that the asymmetric standard deviation is due to the logarithmic scale, and (b) the pore size distribution for $1300{ }^{\circ} \mathrm{C}$ sintered samples, measured using

$\mathrm{Hg}$ intrusion porosimeter as a function of pore diameter.

\subsection{Flexural Strength Results}

The flexural strength $(\sigma)$ of ceramics, from 4-point bending experiments, can be estimated using Equation 3 [27].

$$
\text { Flexural strength }(\sigma)=\frac{3 F d}{b t^{2}}
$$

where $F$ is the maximum load at which the sample fractures, $d, b$ and $t$ are the distance between the support roller and the load roller length $(10 \mathrm{~mm})$, width of the sample $(4 \mathrm{~mm})$ and thickness $(3 \mathrm{~mm})$ of the sample respectively. 
The experimental flexural strength data of sintered alumina samples are plotted as a function of their sintering temperatures, total porosity fraction, open porosity fraction and equivalent grain diameter in Figure 5. In Figure 5a, flexural strength results are plotted for a total of 50 sintered alumina samples to show the scatter for each sintering temperature. It can be observed that the differences in average values are not significantly different for different sintering temperatures. Hence, the average value and standard deviation are not presented in Figure 5a, but we discuss the flexural strength data as a whole. The flexural strength ranged between $262 \mathrm{MPa}$ and 561 MPa for varying sintering temperatures (Figure 5a). Apparently, $1400{ }^{\circ} \mathrm{C}$ sintered samples batch exhibited slightly higher flexural strength values as compared to other sintering batches (Figure 5a). This is due to optimal grain diameters and porosity fraction as compared to others. In detail, the average grain diameter of this $1400{ }^{\circ} \mathrm{C}$ sintered batch of samples is $750 \pm 245 \mathrm{~nm}$ (Figure $3 \mathrm{~b}$ ) and the average total porosity fraction is $2.9 \pm 2 \%$ (Figure $4 \mathrm{a}$ ). However, $1500{ }^{\circ} \mathrm{C}$ sintered batch constitutes, similar total porosity of $2.1 \pm 0.9 \%$ (Figure $4 \mathrm{a}$ ), while possessing a higher average grain diameter of $1587 \pm 863 \mathrm{~nm}$ (Figure 3b). Consequently, the flexural strength in $1400{ }^{\circ} \mathrm{C}$ sintered samples is slightly higher than that of $1500^{\circ} \mathrm{C}$ sintered batch. This is in accordance with literature, which suggests an increase in the flexural strength for a decrease in the grain diameter $[8,10,11,16,33-35]$. On the other hand, although, the samples sintered at $1300{ }^{\circ} \mathrm{C}$ and $1350{ }^{\circ} \mathrm{C}$ have smaller grain sizes than $1400{ }^{\circ} \mathrm{C}$ sintered batch, but possess higher total porosity fractions of $6.7 \pm 2.6 \%$ and $5.2 \pm 2.6 \%$ respectively, which resulted in smaller flexural strength values. This indicates that the total porosity fraction plays a dominant role in governing the flexural strength as compared to the average grain size in mesoporous submicron alumina.

Graphical representations of flexural strength data are shown in Figure 5(b-d) as a function of total porosity fraction, open porosity fraction and equivalent grain diameters to verify if one of them outperforms the other for dictating the strength. Interestingly, a decreasing trend for the strength can be observed for an increase in the total porosity fraction (Figure 5b). However, no special trend can be observed for the flexural strength as a function of open porosity (Figure 5c). These observations indicate that total porosity fraction is a better parameter as compared to that of open porosity fraction in dictating the strength and is in agreement with that described by Rice R. W. et al., [17-20]. It is however, to be noted that the a high scatter in the strength values as a function of total porosity fraction arise due to the fact that the grain sizes of all the samples vary 
significantly and the effect of grain diameter is not de-convoluted. In Figure 5d, the flexural strength of six selected samples with varying grain diameters are plotted. For instance, the strength values of three samples possessing $280 \mathrm{~nm}$ grain diameters are $284 \mathrm{MPa}, 402 \mathrm{MPa}$ and $490 \mathrm{MPa}$. Clearly, the difference in strength arises due to difference in total porosity fraction values which are $12.7 \%, 4.9 \%$ and $3.1 \%$ respectively. Therefore, one must be cautious not to see the virtual decreasing trend of strength with grain diameter as can be majorly seen in Figure $5 \mathrm{~d}$. From the above analysis, it is evident that total porosity fraction is a critical microstructural characteristic as compared to grain diameter in dictating the flexural strength. 

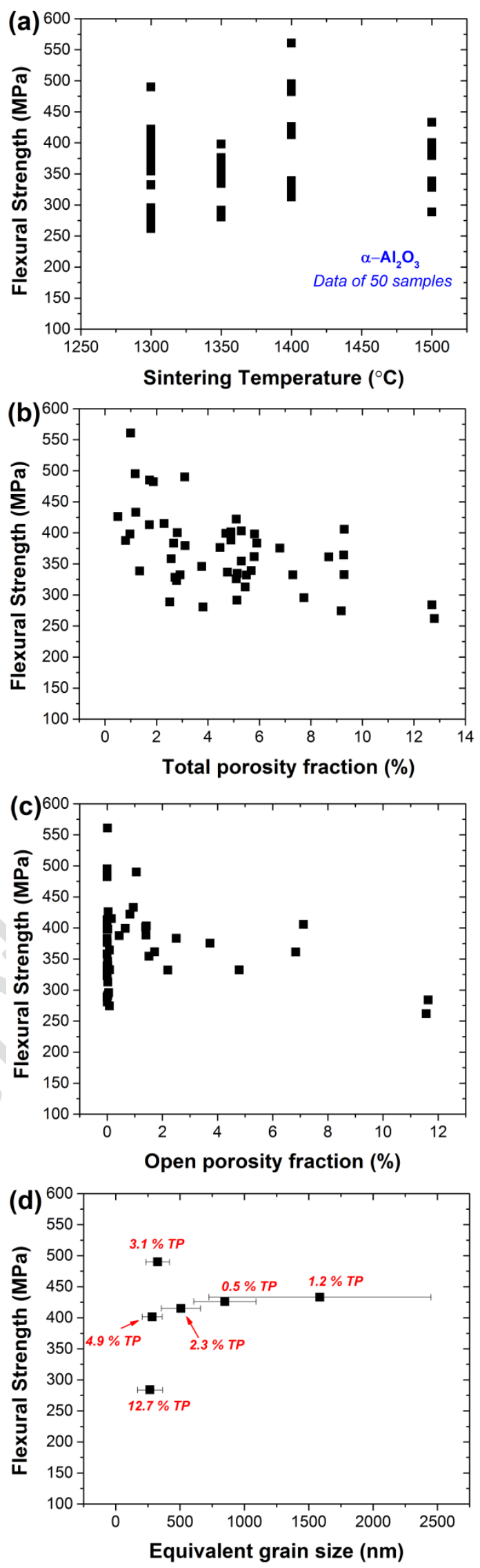
Figure 5. The flexural strength data of $50 \alpha-\mathrm{Al}_{2} \mathrm{O}_{3}$ samples are plotted as a function of their corresponding (a) sintering temperatures, (b) total porosity fraction, (c) open porosity fraction and (c) equivalent grain size respectively.

The collected flexural strength data of $\alpha-\mathrm{Al}_{2} \mathrm{O}_{3}$ samples from literature, with their corresponding grain morphologies, pore morphologies and sample fabrication techniques are graphically presented in Figure 6 for a comparison. The fabrication techniques employed in literature are hot pressing $(\boldsymbol{H P})$, hot isostatic pressing $(\boldsymbol{H I P})$, cold pressing $(\boldsymbol{C P})$, foaming $(\boldsymbol{F})$ and slip casting (SC) followed by sintering $(\boldsymbol{S})$ [8],[9],[10],[11],[12]. In Figure 6a, it can be seen that, for the fully dense alumina samples, the flexural strength decreased exponentially with an increase in the grain size [8],[9],[10],[11]. It is evident that, in all those studies (see inset of Figure 6a), only microcrystalline grains were used. Secondly, the grain shape in most of the studies is equiaxed, except one study where elongated grains [9] are generated post sintering of hot isostatically pressed samples. These elongated grains are similar to that observed in our $1500{ }^{\circ} \mathrm{C}$ sintered samples, except that the rods in the literature [9] have smaller aspect ratios $(\sim 2-2.5)$. Interestingly, the flexural strength values of $1500{ }^{\circ} \mathrm{C}$ samples is $367 \pm 43 \mathrm{MPa}$ (Figure $5 \mathrm{~b}$ ) and match closely with that reported in literature (400 MPa) [9].

Our flexural strength values are as high as $560 \mathrm{MPa}$ or on an average $410 \pm 87 \mathrm{MPa}$ for fully dense sintered samples (Figure 5a). However, flexural strength of fully dense slip cast ultrafined alumina samples was reported to be only $170 \mathrm{MPa}$ (see Figure 6a) [12]. In another study, slip cast $95 \%$ dense alumina (grain diameter $=23 \mu \mathrm{m}$, closed pore diameters of $\sim 100 \mu \mathrm{m}$ ) was shown to possess slightly improved strength of $220 \mathrm{MPa}$ [15] (see Figure 6b). Although, same slip casting process was employed in our work and that in literature [15], our strength values are 2.5 times higher and mainly attributed to the difference in pore sizes. We have used samples containing connected mesoporous network, in contrast to the bimodal pore sizes employed in literature [15], out of which the largest pores are macro isolated pores (diameters of $\sim 100 \mu \mathrm{m}$ ). This is in accordance with literature [14], which reported a 6 times decrease in the flexural strength (from $38 \mathrm{MPa}$ to $6 \mathrm{MPa}$ ) of slip-cast pre-sintered and glass infiltrated alumina for increase in the average pore sizes from $0.2 \mu \mathrm{m}$ to $1 \mu \mathrm{m}$ and for relatively broad pore size distributions, but constituting comparable grain sizes. Additional contributing factors for improved strength are submicron grain sizes in this work, and possible improved de-agglomeration steps in the slurry 
preparation of slip casting process. On the contrary, fully dense alumina samples comprising equiaxed ultrafine grains $(750 \pm 245 \mathrm{~nm}$ grain size $)$ in the current study, demonstrate flexural strength of $410 \pm 87 \mathrm{MPa}$ and closely match with that of $\sim 1 \mu \mathrm{m}$ sized $\mathrm{Al}_{2} \mathrm{O}_{3}$ fabricated by hot pressing, as reported in literature (460 MPa) [8],[10].

The literature obtained flexural strength data of porous alumina samples and foams, for varying total porosity fraction and pore diameter, are presented in Figure $6 \mathrm{~b}$, where pore fraction varied between $5 \%$ and $94 \%$, and pore sizes between $90 \mathrm{~nm}$ and $500 \mu \mathrm{m}$. The grains are equiaxed and grain diameters varied between $500 \mathrm{~nm}$ and $23 \mu \mathrm{m}$. It suggests that the effect of mesopores (pore diameters between $2 \mathrm{~nm}$ and $50 \mathrm{~nm}$ ) on the flexural strength of alumina samples was not reported in the literature. Briefly, the flexural strength values varied between 1.94 $\mathrm{MPa}$ (for foams) and $220 \mathrm{MPa}$. In another study [35], it was demonstrated that flexural strength of amorphous anodized microporous (pore diameter $>50 \mathrm{~nm}$ ) alumina decreased from $182 \mathrm{MPa}$ to $48 \mathrm{MPa}$ for an increase in the porosity from $22.7 \%$ to $51.7 \%$, suggesting a decreasing trend for strength as a function of porosity fraction, similar to our analysis. In a recent report [16], ultrafine $95 \%$ dense alumina (grain diameter of $150 \mathrm{~nm}$ ) fabricated by sol-gel and sintering techniques, showed a flexural strength of $420 \mathrm{MPa}$, which is in the same range as that of $1350{ }^{\circ} \mathrm{C}$ samples batch in the current study. However, this article is not exhaustive because, the pore size data and reproducibility of the flexural strength data were not reported. Henceforth, this data is not presented in Figure 6.
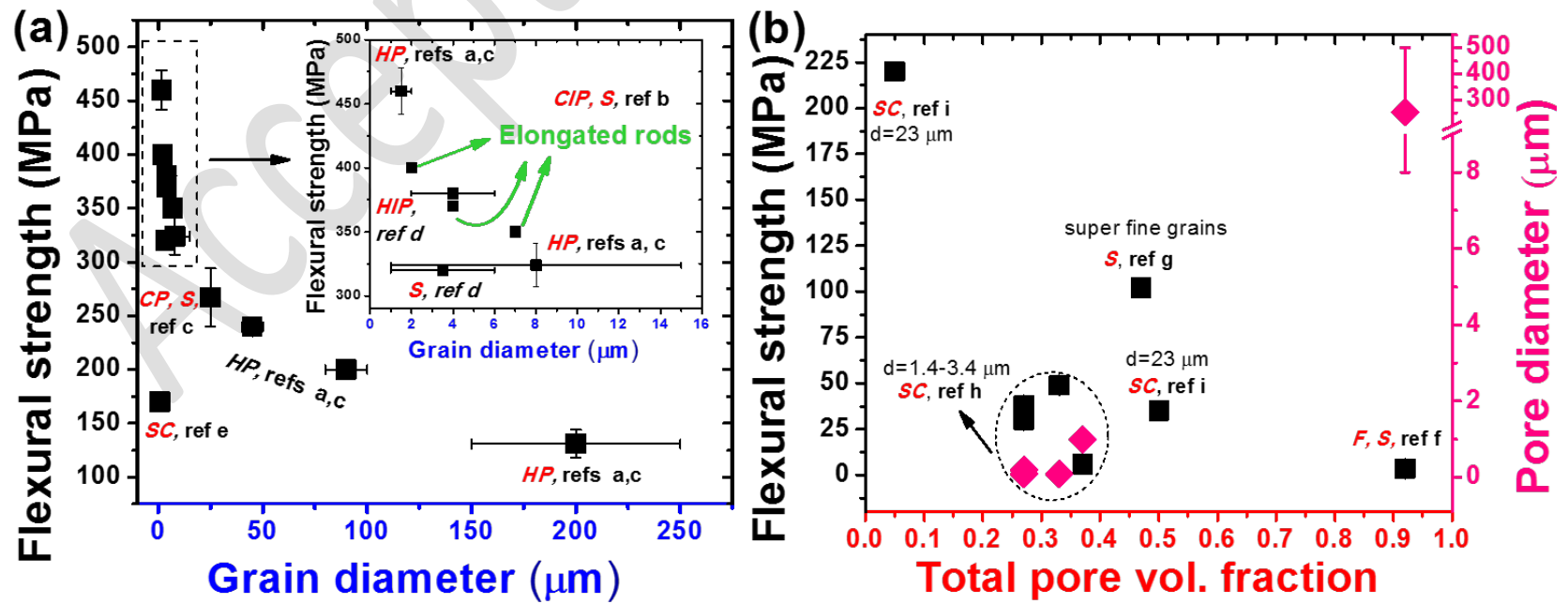

Figure 6. Graphical summary of flexural strength data of $\alpha-\mathrm{Al}_{2} \mathrm{O}_{3}$ samples collected from literature and presented as a function of (a) grain diameter, for fully dense samples and (b) total pore fraction, giving 
details of pore diameters, wherever available. The notations used in the graphs are described as $\boldsymbol{C P}$-Cold Pressing, $\boldsymbol{H P}$-Hot Pressing, $\boldsymbol{H I P}$-Hot Isostatic Pressing, $\boldsymbol{S}$-Sintering, $\boldsymbol{S C}$-Slip Casting, $\boldsymbol{F}$-Foaming and are the employed fabrication techniques. The ref a, b, c, d, e, f, g, h and i are the references[8],

$[9],[10],[11],[12],[1],[4],[14],[15]$ respectively.

The flexural strength values of $1400{ }^{\circ} \mathrm{C}$ sintered samples from this study are typically between $320 \mathrm{MPa}$ and $560 \mathrm{MPa}$, and comparable to that of glass infiltrated micro-grained (diameter = $2.85 \mu \mathrm{m})$ alumina $(490 \pm 90 \mathrm{MPa})$ [25]. Therefore, our results indicates that submicron alumina samples possess much higher strength values as compared to microcrystalline alumina composites and may be a replacement for clinical purposes by further optimization of grain morphology.

\subsection{Fractography Analyses}

Fractography analyses were carried out to investigate the fractured surfaces immediately post 4point bending tests. It was observed that all samples were fractured into either 2 or 3 pieces. High resolution SEM was performed on at least two samples from each sintering batch for reproducibility. In Figure 7, the fractographs of alumina samples sintered at $1300{ }^{\circ} \mathrm{C}$ and $1350{ }^{\circ} \mathrm{C}$ are presented. In Figure 7(a-b), overviews of several cracks at low and high magnifications are shown. Typical crack lengths range between $1 \mu \mathrm{m}$ and $800 \mu \mathrm{m}$. For samples sintered at $1300{ }^{\circ} \mathrm{C}$, the fractured surfaces mostly showed intergranular fracture, with negligible transgranular fracture as evident from Figure 7(c-d). The deflection of cracks at the grain boundaries was observed at several locations (Figure 7c), thus indicating intergranular fracture. The cracks present in these samples have crack diameters ranging between $300 \mathrm{~nm}$ and $5 \mu \mathrm{m}$ (Figure 7(c-d)). Further, there are heterogeneous microstructured regions, which were revealed by fracture and shown in Figure 7(e-f). This microstructure comprises of a region which resembles more to a fully sintered and monocrystalline flat part, and another region, comprising polycrystallites. Similarly, few selected fractographs of sample sintered at $1350{ }^{\circ} \mathrm{C}$ are presented in Figure $7(\mathrm{~g}$-i). Overview pictures of fractured surfaces are showcased, and clear indication of intergranular fracture is observed. In brief, $1300{ }^{\circ} \mathrm{C}$ and $1350{ }^{\circ} \mathrm{C}$ sintered samples fracture predominantly by intergranular fracture. 


\section{$1300{ }^{\circ} \mathrm{C}$ sintered}
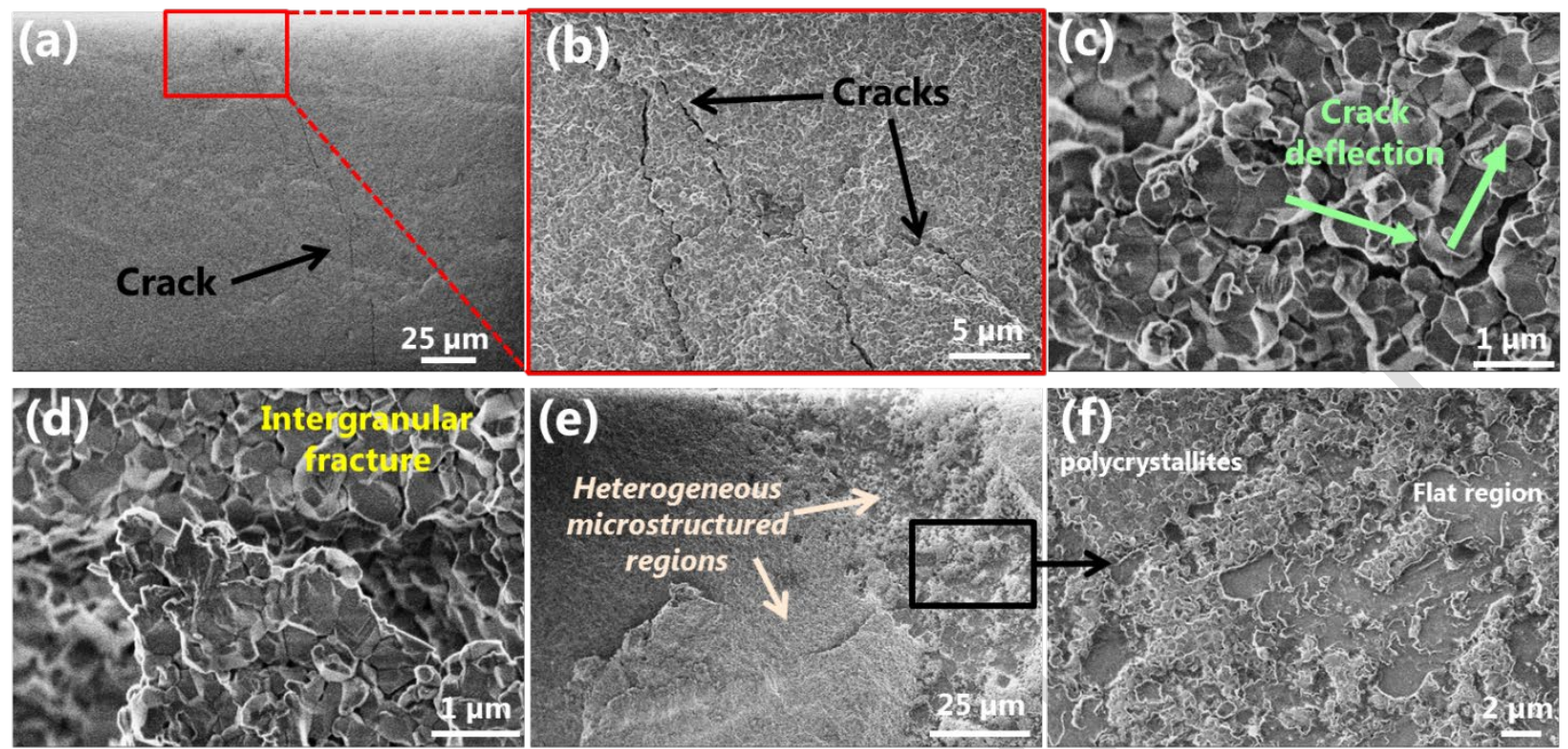

\section{$1350{ }^{\circ} \mathrm{C}$ sintered}
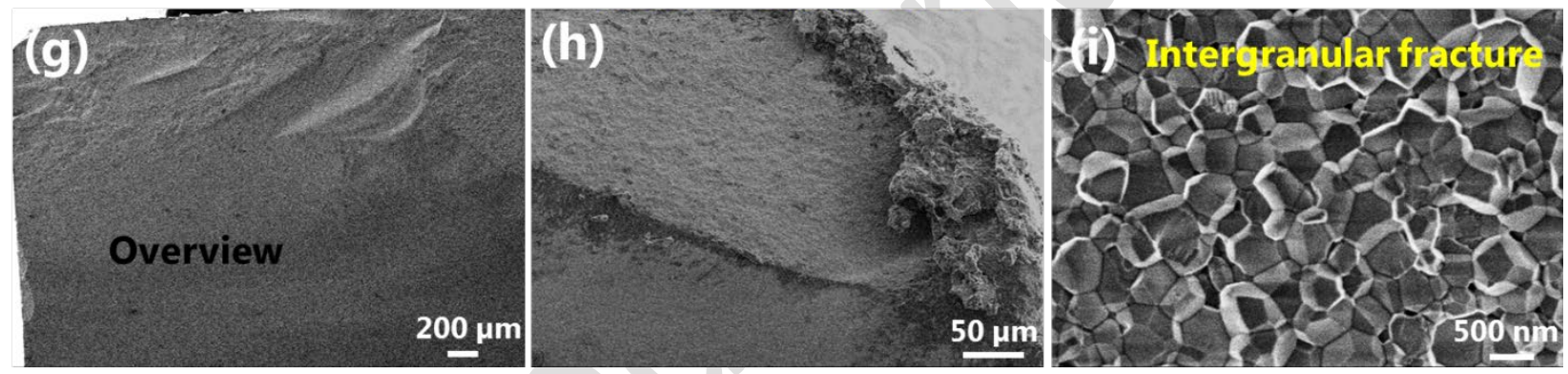

Figure 7. (a-f) A series of SEM fractographs for samples sintered at $1300{ }^{\circ} \mathrm{C}$, (c) A crack deflection can be seen indicating intergranular fracture, (d) heterogeneous microstructures were revealed by fracture at several locations. (g-i) A series of SEM fractographs for samples sintered at $1350{ }^{\circ} \mathrm{C}$.

Subsequently, the SEM fractographs of alumina samples sintered at $1400{ }^{\circ} \mathrm{C}$ and $1500{ }^{\circ} \mathrm{C}$ are presented in Figure 8. In $1400{ }^{\circ} \mathrm{C}$ sintered samples, the fractured surfaces possess numerous cracks as shown in Figure 8a. Long cracks, typically between $50 \mu \mathrm{m}$ and $1.5 \mathrm{~mm}$ were observed in these samples as demonstrated in Figure 8(a,b-c, g). These cracks constitute crack diameters between $1 \mu \mathrm{m}$ to $10 \mu \mathrm{m}$ (see Figure 8(b-d)). The fracture energy depends on the volume fraction and the average grain size of alumina [25],[36-38]. This justifies the presence of bigger cracks in these samples, as compared to those sintered at lower temperatures $\left(1300{ }^{\circ} \mathrm{C}\right.$ and $\left.1350{ }^{\circ} \mathrm{C}\right)$. In contrast to samples sintered at $1300{ }^{\circ} \mathrm{C}$ and $1350{ }^{\circ} \mathrm{C}$, these samples exhibit both intergranular and transgranular fracture modes (Figure 8(d-f)). A cross-section of transgranular cleavage is shown in Figure 8e and a crack deflection at grain boundaries (or called intergranular fracture) is shown 
in Figure 8f. It is to be noted that transgranular fracture type was not observed for mesoporous alumina samples sintered at $1300{ }^{\circ} \mathrm{C}$ and $1350{ }^{\circ} \mathrm{C}$, because these samples possess weaker grain boundaries as compared to the bulk grain and hence fractured majorly by intergranular fracture type. The major strengthening mechanism in these samples is crack deflection at grain boundaries and similar to that proposed by R. Guo et al. [39]. Similar fractographs were observed in glass infiltrated alumina samples, which possessed rod shaped micro grains [25]. A combination of intergranular and transgranular fracture modes were also reported in literature [8] in fine grained (1-2 $\mu \mathrm{m})$ hot pressed fully dense equiaxed alumina, and is consistent with our observations.

$1400{ }^{\circ} \mathrm{C}$ sintered
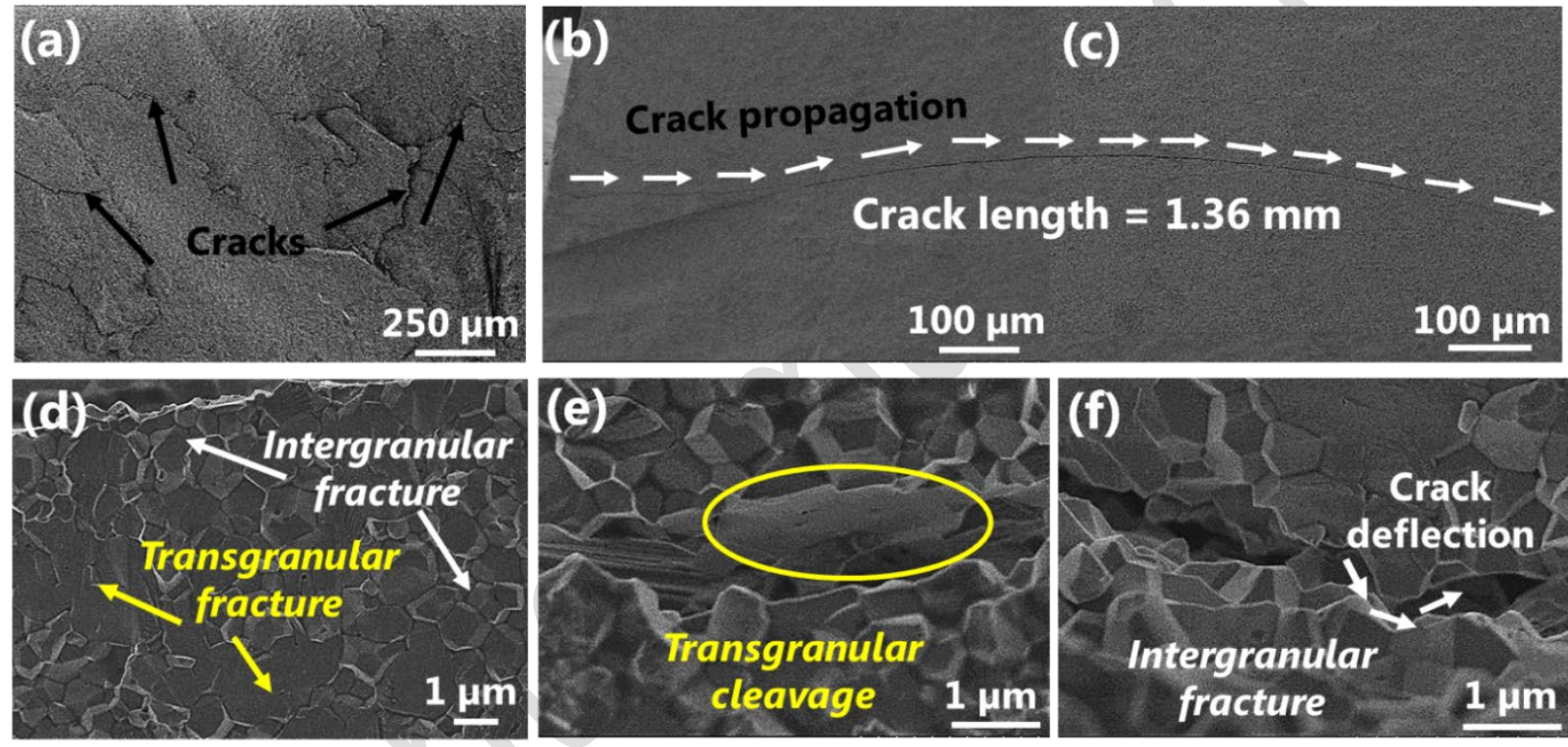

\section{$1500{ }^{\circ} \mathrm{C}$ sintered}
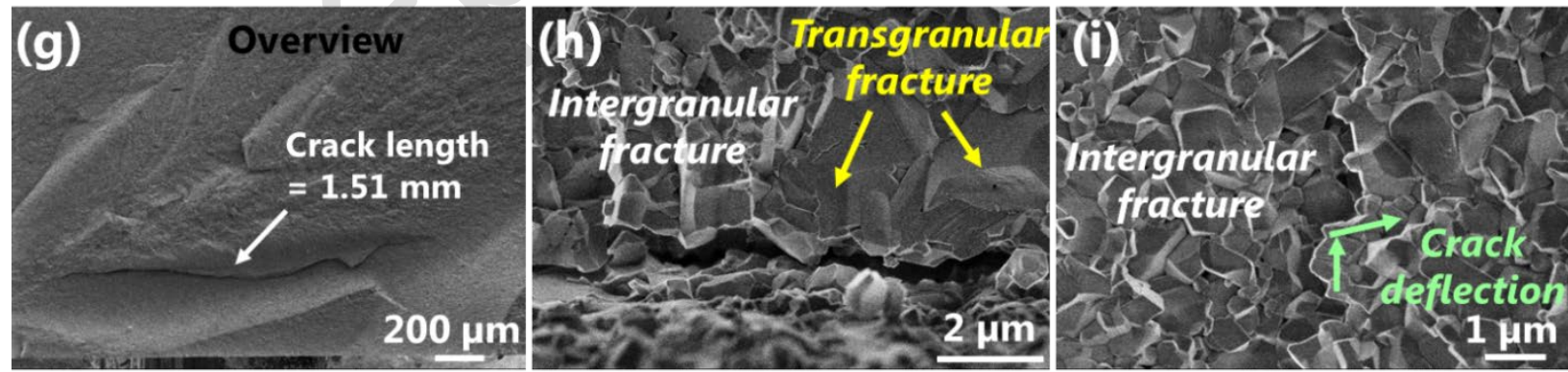

Figure 8. (a-f) A series of SEM fractographs for samples sintered at $1400{ }^{\circ} \mathrm{C}$, are presented. In (a), an overview of several cracks is presented. In (b-c), a single long crack with crack length of $>1.36 \mathrm{~mm}$ is shown by merging two SEM images. In (d) regions that underwent intergranular and transgranular fracture types are shown and in (e) cross-section of a transgranular cleavage is presented while in (f), crack deflection at the grain boundary is shown indicating intergranular fracture. (g-i) A series of SEM fractographs for samples sintered at $1500{ }^{\circ} \mathrm{C}$ are presented. 


\section{Conclusions}

Slip casting process, followed by conventional sintering of ultrafine $\alpha-\mathrm{Al}_{2} \mathrm{O}_{3}$ powders at 1300 ${ }^{\circ} \mathrm{C}, 1350{ }^{\circ} \mathrm{C}, 1400{ }^{\circ} \mathrm{C}$ and $1500{ }^{\circ} \mathrm{C}$ resulted in a variety of grain morphologies and pore fractions with a mesoporous network. Sintered $\alpha-\mathrm{Al}_{2} \mathrm{O}_{3}$ samples result in submicron equiaxed grains and microcrystalline rod structures. The total pore fraction varied between $0.05 \%$ and $13 \%$. The room temperature 4-point bending experiments and fractography analyses have been performed and the main conclusions are presented as follows:

1. Combinatorial influence of grain morphology and pore fraction on the flexural strength has been investigated. Qualitative observations suggest that the total pore fraction seems to be a dominant factor in governing the strength as compared to grain size.

2. Flexural strength data exhibited a decreasing trend for an increase in the total porosity fraction and demonstrates that, total porosity fraction is a better microstructural parameter as compared to open porosity.

3. Slightly high flexural strength values were observed for the $1400{ }^{\circ} \mathrm{C}$ sintered batch of samples as compared to other sintering temperatures owing to ultrafine grains and least porosity.

4. The best attained flexural strength values in this current study $(410 \pm 87 \mathrm{MPa})$, are in the

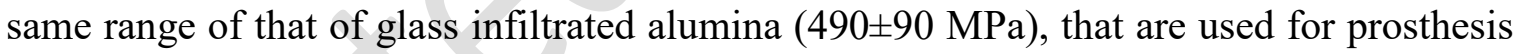
purposes. Therefore, single phase ultrafine alumina may be explored to replace glass infiltrated alumina.

5. The fractography analyses suggest that samples sintered at $1300{ }^{\circ} \mathrm{C}$ and $1350{ }^{\circ} \mathrm{C}$ exhibited predominantly intergranular fracture. While, in samples sintered at $1400{ }^{\circ} \mathrm{C}$ and $1500{ }^{\circ} \mathrm{C}$, the fracture mechanisms are a mixture of intergranular and transgranular fracture modes. And, the crack deflection is a major strengthening mechanism in the latter samples.

\section{Author Contributions}

Sriharitha Rowthu conceived and prepared the samples, carried out microstructural characterizations, fractography analyses and wrote the complete manuscript. Jakob Kuebler aided in the 4-point bending experiments and strongly contributed to the scientific analyses. Fatemeh 
Saeidi aided in the sintering and density measurements. Fatemeh Saeidi, Kilian Wasmer and Patrik Hoffmann contributed to the manuscript revision.

\section{Acknowledgements}

The authors thank CCMX, Switzerland and Bobst Mex SA for funding the project under project number 5211.00093.100.01. The authors are grateful to Elias Stutz, a previous internship student at Empa Thun for assisting in the slip casting. Erwin Pieper and Roland Bächtold from Empa Dübendorf are acknowledged for grinding and chamfering the samples, and for performing 4point bending tests respectively. The authors acknowledge Prof. Paul Bowen, LTP EPFL for his guidance in slip casting. The authors also thank Prof. John Botsis and his team, LMAF, EPFL for their participation in the CCMX project.

\section{References}

[1] B.S.M. Seeber, U.T. Gonzenbach, L.J. Gauckler, Mechanical properties of highly porous alumina foams, Journal of Materials Research. 28 (2013) 2281-2287.

[2] A. Pyzik, R. Ziebarth, C. Han, K. Yang, High-Porosity Acicular Mullite Ceramics For Multifunctional Diesel Particulate Filters, International Journal of Applied Ceramic Technology. 8 (2011) 1059-1066.

[3] K. Schlichting, N. Padture, P. Klemens, Thermal conductivity of dense and porous yttriastabilized zirconia, Journal of Materials Science. 36 (2001) 3003-3010.

[4] X. Luo, Y. Zhao, J. Tian, Y. Chao, S. Zhang, Y. Zhang, Research on bending strength and fracture toughness of alumina-glass composite, Journal of West China University of Medical Sciences. 29 (1998) 383-386.

[5] F. Da Silva, A. Barbejat, others, Influence of handling and heating cycle on the morphology and flexural strength of glass-infiltrated alumina bars, Matéria (Rio de Janeiro). 13 (2008) 49-55.

[6] P. Chantikul, S.J. Bennison, B.R. Lawn, Role of grain size in the strength and r-curve properties of alumina, Journal of the American Ceramic Society. 73 (1990) 2419-2427.

[7] S. Graça, V. Trabadelo, A. Neels, J. Kuebler, V. Le Nader, G. Gamez, et al., Influence of mosaicity on the fracture behavior of sapphire, Acta Materialia. 67 (2014) 67-80.

[8] R. Spriggs, J. Mitchell, T. Vasilos, Mechanical properties of pure, dense aluminum oxide as a function of temperature and grain size, Journal of the American Ceramic Society. 47 (1964) 323-327. 
[9] R. Singha Roy, M. Mitra, D. Basu, Characterization of mechanical properties of alumina based hip joint prostheses, Trends in Biomaterials and Artificial Organs. 18 (2005) 166173.

[10] G. Henshall, N. Nguyen, Ambient temperature fracture strength of pure alumina, 1990.

[11] M. Munro, Evaluated Material Properties for a Sintered alpha-Alumina, Journal of the American Ceramic Society. 80 (1997) 1919-1928.

[12] L. Pröbster, J. Diehl, Slip-casting alumina ceramics for crown and bridge restorations., Quintessence International. 23 (1992).

[13] J. Kübler, F. Clemens, E. Aquino, T. Graule, Correlation between properties of extruded $\mathrm{ZrO} 2$ rods in the green and sintered states, Adv. Sci. Technol. 30. (2002) 701-708.

[14] P. Bajpai, P. Bhargava, Effect of Pore Characteristics in Slip Cast Alumina on Glass Infiltration and Mechanical Properties of the Composites, International Journal of Applied Ceramic Technology. 9 (2012) 625-635.

[15] R. Coble, W. Kingery, Effect of porosity on physical properties of sintered alumina, Journal of the American Ceramic Society. 39 (1956) 377-385.

[16] E. Zemtsova, A. Monin, V. Smirnov, B. Semenov, N. Morozov, Formation and mechanical properties of alumina ceramics based on $\mathrm{Al} 2 \mathrm{O} 3$ micro-and nanoparticles, Physical Mesomechanics. 18 (2015) 134-138.

[17] R. Rice, Evaluation and extension of physical property-porosity models based on minimum solid area, Journal of Materials Science. 31 (1996) 102-118.

[18] J. Li, H. Lin, J. Li, Factors that influence the flexural strength of SiC-based porous ceramics used for hot gas filter support, Journal of the European Ceramic Society. 31 (2011) 825831.

[19] R. Rice, Comparison of physical property-porosity behaviour with minimum solid area models, Journal of Materials Science. 31 (1996) 1509-1528.

[20] R.W. Rice, Evaluating porosity parameters for porosity-property relations, Journal of the American Ceramic Society. 76 (1993) 1801-1808.

[21] E. Ryshkewitch, Compression strength of porous sintered alumina and zirconia, Journal of the American Ceramic Society. 36 (1953) 65-68.

[22] S. Rowthu, K. Böhlen, P. Bowen, P. Hoffmann, Surface 3D Micro Free Forms: Multifunctional Microstructured Mesoporous alpha-Alumina by In-Situ Slip Casting Using Excimer Laser Ablated Polycarbonate Molds, ACS Applied Materials $\backslash \&$ Interfaces. 7 (2015) 22458-22469. 
[23] S. Rowthu, Self-Replenishing, Wear-Resistant and Anti-Sticking Surfaces Based on Liquid Impregnation of Microstructured Mesoporous alpha- $\mathrm{Al}_{2} \mathrm{O}_{3}$ Matrices, $\mathrm{PhD}$ dissertation, Ecole Polytechnique Fédérale de Lausanne, doi:10.5075/epfl-thesis-7024, 2016.

[24] S. Rowthu, E.E. Balic, P. Hoffmann, Molecular Dimensions and Surface Diffusion Assisted Mechanically Robust Slippery Perfluoropolyether Impregnated Mesoporous Alumina Interfaces, Nanotechnology. 28 (2017) 505605.

[25] D.Y. Lee, D.-J. Kim, B.-Y. Kim, Y.-S. Song, Effect of alumina particle size and distribution on infiltration rate and fracture toughness of alumina-glass composites prepared by melt infiltration, Materials Science and Engineering: A. 341 (2003) 98-105.

[26] P.E. Wells, Porosities and seismic velocities of mudstones from Wairarapa and oil wells of North Island, New Zealand, and their use in determining burial history, New Zealand Journal of Geology and Geophysics. 33 (1990) 29-39.

[27] C. ASTM, 1161-13, “ Standard Test Method for Flexural Strength of Advanced Ceramics at Ambient Temperature,", American Society for Testing and Materials Annual Book of Standards. (1990) 1-19.

[28] M. Guazzato, M. Albakry, L. Quach, M.V. Swain, Influence of grinding, sandblasting, polishing and heat treatment on the flexural strength of a glass-infiltrated aluminareinforced dental ceramic, Biomaterials. 25 (2004) 2153-2160.

[29] S. Inada, T. Kimura, T. Yamaguchi, Effect of green compact structure on the sintering of alumina, Ceramics International. 16 (1990) 369-373.

[30] D.-M. Liu, Influence of solid loading and particle size distribution on the porosity development of green alumina ceramic mouldings, Ceramics International. 23 (1997) 513520 .

[31] P.A. Smith, R.A. Haber, Reformulation of an Aqueous Alumina Slip Based on Modification of Particle-Size Distribution and Particle Packing, Journal of the American Ceramic Society. 75 (1992) 290-294.

[32] C. Tallon, M. Limacher, G.V. Franks, Effect of particle size on the shaping of ceramics by slip casting, Journal of the European Ceramic Society. 30 (2010) 2819-2826.

[33] R. Spriggs, T. Vasilos, Effect of grain size on transverse bend strength of alumina and magnesia, Journal of the American Ceramic Society. 46 (1963) 224-228.

[34] V. Sirota, E. Gevorkyan, M. Kovaleva, V. Ivanisenko, Structure and properties of nanoporous ceramic A12O3 obtained by isostatic pressing, Glass and Ceramics. 69 (2013) $342-345$. 
[35] J.-H. Chen, W.-S. Luo, Flexural Properties and Fracture Behavior of Nanoporous Alumina film by Three-Point Bending Test, Micromachines. 8 (2017) 206.

[36] F. Lange, Fracture Energy and Strength Behavior of a Sodium Borosilicate Glass-A12O3 Composite System, Journal of the American Ceramic Society. 54 (1971) 614-620.

[37] D. Hasselman, R. Fulrath, Proposed fracture theory of a dispersion-strengthened glass matrix, Journal of the American Ceramic Society. 49 (1966) 68-72.

[38] D.-J. Kim, M.-H. Lee, C.-E. Kim, Mechanical Properties of Tape-Cast Alumina-Glass Dental Composites, Journal of the American Ceramic Society. 82 (1999) 3167-3172.

[39] R. Guo, D. Guo, Y. Chen, Z. Yang, Q. Yuan, In situ formation of LaAl 11 O 18 rodlike particles in ZTA ceramics and effect on the mechanical properties, Ceramics International. 28 (2002) 699-704. 